\title{
Escritura colaborativa y digital para la motivación hacia la literatura solidaria: cuentos y versos en igualdad
}

\author{
García Carcedo, Pilar \\ Universidad Complutense \\ pcarcedo@ucm.es
}

Santamaría Balcabao, Alejandro

Colegio de Jesús

\section{Resumen}

Introducción: Esta comunicación explora los roles de la literatura de tradición oral, la poesía y la escritura creativa digital en una educación solidaria por la igualdad. Desgraciadamente la educación actual en occidente provee sobre todo valores necesarios solo para el triunfo y la competitividad, será la literatura la principal encargada de inculcar los valores humanísticos universales para la empatía y la igualdad.

Metodología: Con el objetivo de desarrollar la competencia lectora y el análisis crítico en las aulas a partir de modelos literarios proponemos la escritura creativa como el principal recurso didáctico. Inspirar a los estudiantes para que desarrollen una pasión por la escritura y por la lectura comprensiva es la mejor manera de generar complicidad con la literatura. Se propone un trabajo por proyectos centrado en la escritura creativa y digital de cuentos tradicionales y poesía, ya que se han creado también versiones en internet.

Resultados: La experiencia se ha realizado ya con resultados muy satisfactorios en las aulas de la Facultad de Educación de la Universidad Complutense y en el Colegio de Jesús durante el curso 2017- 2018. Una selección de los resultados creativos para la didáctica de la literatura se puede consultar en nuestra página web: Tropos, Biblioteca digital para la escritura creativa: repositorios.fdi.ucm.es/Tropos.

\section{Abstract}

Introduction: This paper explores the roles of traditional literature, poetry and creative digital writing in educating for solidarity and equality. Modern Education mostly provides market values necessary for running economic institutions and it is Literature that fills this gap by inculcating universal, humanistic values.

Methodology: In order to develop analytical skills in-class discussion of readings we propose creative writing as the main didactic resource. Inspire your students to develop a passion for writing and practice reading comprehension is the best way to generate complicity with literature. We propose a PBL, Project- based learning about Creative Digital Writing of Traditional tales and Poetry versions.

Results: This Project has been tested with satisfactory results at the Complutense University and at Jesus School during 2017-2018 academic year. A selection of results can be consulted in our web page: Tropos, Digital Library for Creative Writing, repositorios.fdi.ucm.es/Tropos.

Palabras clave: Escritura creativa y digital. Poesía. Cuentos tradicionales. Didáctica. Promoción de la lectura. Biblioteca Digital.

Keywords: Creative Writing. Fairy tales. Poetry. Didactics. Reading Promotion. Digital Library.

\section{INTRODUCCIÓN}

\author{
Alguna vez soñamos \\ con un mundo distinto. \\ (Luis García Montero)
}

En la educación para un mundo con sueños de paz, de justicia y de igualdad hay que partir de la realidad, a veces dolorosa, para desarrollar la imaginación y llegar hasta la utopía (Moreau, 2017). En estas páginas lo vamos a hacer a través de una selección de modelos literarios para desarrollar la escritura creativa y digital en las aulas. Las propuestas más novedosas en torno a la enseñanza 
de la poesía para secundaria (Moreno, 2012; Mendoza 2010, Ortega, 2011, Delmiro 2002...) siguen considerando que en la didáctica de la literatura predomina un modelo historicista y memorístico; por ello recomiendan proyectos que fomenten la lectura activa, la escritura creativa y la vinculación de la poesía con la realidad.

En esta comunicación se propone la escritura colaborativa digital en las aulas y se presenta nuestro proyecto de investigación-acción que se viene desarrollando en las aulas de la Facultad de Educación de la Universidad Complutense de Madrid con los siguientes objetivos principales:

- Aumentar el placer por la lectura activa de la poesía y de los cuentos tradicionales a través de la escritura creativa en lasaulas.

- Crear antologías temáticas para la educación emocional y la formación en valores y tomarlas como modelo para la escritura.

- Motivar la creatividad a través de la escritura con tecnologías digitales y de remediaciones ${ }^{1}$ multimedia. $^{2}$

- Ampliar nuestra Biblioteca digital de escritura creativa :Tropos, para ofrecer objetos didácticos de aprendizaje online que pueden ser reutilizados por otros profesores para la práctica docente.

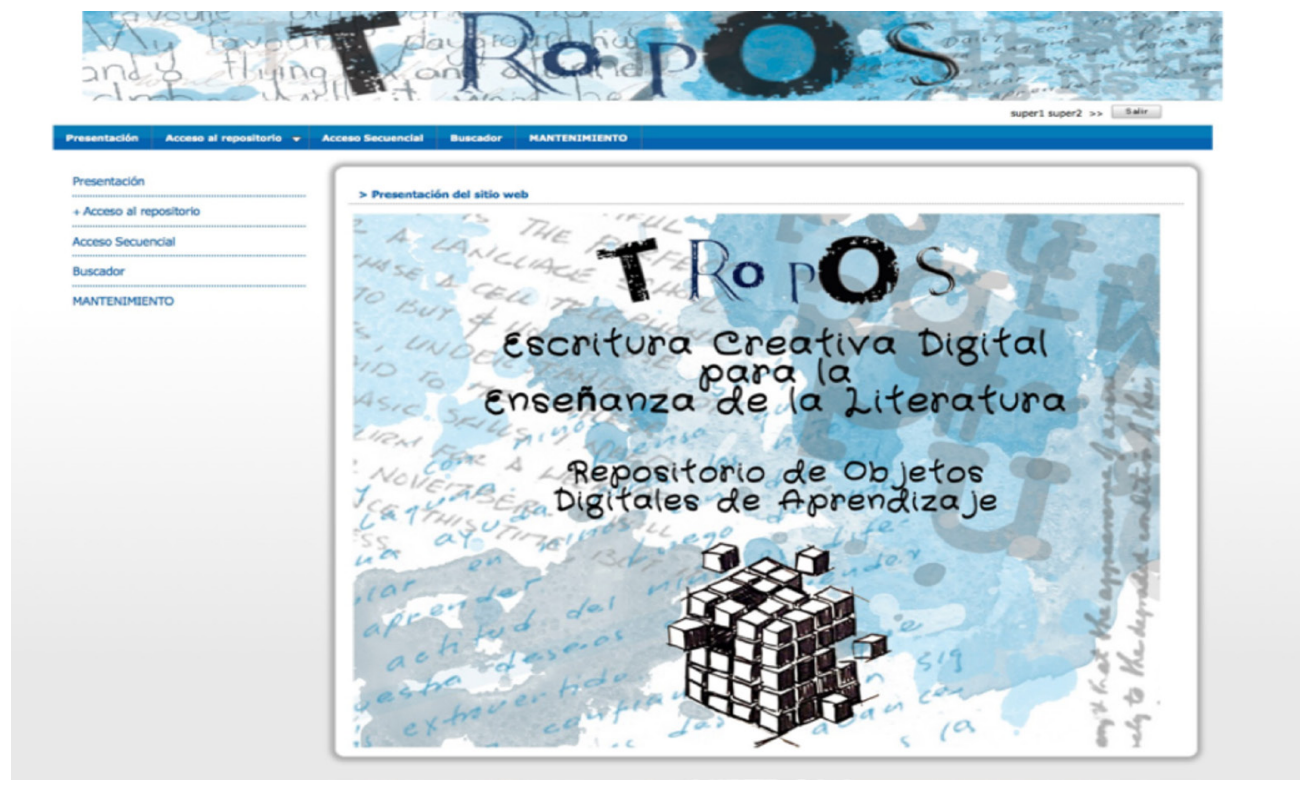

Web de nuestra Biblioteca digital Tropos: repositorios.fdi.ucm.es/Tropos.

Una página en línea creada por el grupo LEETHi en la que se ofrecen ejemplos sobre la necesidad de modificar los paradigmas didácticos en base a los cambios de nuestras nuevas sociedades digitalizadas. El objetivo es ofrecer una selección de las creaciones y actividades de remediación literaria de los alumnos de la Universidad Complutense en las Facultades de Educación y Filología, cada uno de los objetos digitales viene explicado en una ficha didáctica para que puedan ser modelos reutilizables en todas las aulas.

\section{ESCRITURA DIGITAL EN LAS AULAS Y BIBLIOTECA TROPOS}

¿Por qué recurrir a la escritura digital en las aulas? Muy sencillo, los jóvenes del siglo XXI leen y escriben más que nunca en pantallas (Mendoza 2010). La Federación de Gremios de Editores de España (FGEE) ha publicado en 2018 el «Barómetro de Hábitos de Lectura y Compra de Libros ${ }^{2}$ ». Según los datos de dicho estudio, el $76,3 \%$ de los españoles mayores de catorce años leen algún tipo

\footnotetext{
${ }^{1}$ Remediación en términos de nuevos medios digitales, es la representación de un medio en otro. En nuestro caso nos referimos a la reescritura de modelos literarios utilizando las posibilidades multimedia que ofrecen las nuevas tecnologías (imágenes, sonidos, videos, etc.) 2 http://federacioneditores.org/img/documentos/HabitosLecturaCompraLibros2017. pdf (consultado en marzo de 2018). Parece, según este estudio, que el formato no indica que leer en digital sea sinónimo de lectura «ligera»; la mayoría de los lectores digitales son mujeres con alto nivel formativo. En cuanto a los soportes, las tabletas (32,8\%) y los móviles $(20,2 \%)$ siguen siendo los favoritos.
} 
de contenido en soporte digital, 18 puntos más que en 2012. En referencia a la lectura de ficción, un veinte por ciento lee solo en soporte digital, en este caso refiriéndose también a lectura por ocio, no por trabajo o estudio. Además, como en estudios anteriores, el perfil del lector digital es el de un lector más intensivo, que lee una media de 16,7 libros al año, frente a los 11,6 del lector que sólo lee en papel.

En la educación del siglo XXI es necesario investigar asimismo los cambios que provoca la incursión de los ordenadores en el campo de la lectura y en las escrituras literarias, ya que los procesos de lectura están cada vez más asociados a ese mundo digital, sea a través de obras digitalizadas, de textos literarios escritos específicamente para un soporte digital o a través de blogs, fanfics o redes sociales, ámbitos de ocio especialmente atractivos para la juventud. No se trata solo de un desafío para la literatura, sino también para la enseñanza, los profesores nos enfrentamos al reto de aprovechar esa afición juvenil por la tecnología; ya que es necesario formar mentes creativas en el acceso a la comunicación digital y aprender a conocer las variantes que estos nuevos medios introducen en los modos de lectura y escritura (García Carcedo, 2008 y 2015, Delmiro 2002). La didáctica tiene que hacerse más flexible, no centrarse en la mera transmisión de conocimientos sino en el fomento de la creatividad y del espíritu crítico.

Por eso en esta propuesta se parte de antologías temáticas que se utilizan como modelo literario para talleres de escritura que fomentan el aprendizaje libre a partir de los versos de los maestroscuidadosamente elegidos para tal fin. La escritura creativa afortunadamente viene adquiriendo importancia en la práctica educativa, al menos en Educación Primaria, gracias a la adopción de las propuestas de Gianni Rodari (2002), y de otros talleres literarios como los de Victor Moreno (1995) o Esperanza Ortega (2011) por poner solo dos ejemplos entre los que han contribuido a la renovación de la enseñanza. Para profundizar en la extensa gama de posibilidades de la escritura colaborativa se pueden revisar los distintos tipos de talleres en la obra de Gardner (2001).

En este caso, los resultados digitales de nuestra experiencia creativa, realizados por los alumnos de «Literatura y educación» de Magisterio Primaria, se pueden encontrar como hemos dicho en la Biblioteca digital de escritura creativa Tropos. Por poner algunos ejemplos de los objetos didácticos seleccionamos los siguientes:

- Se puede trabajar por la igualdad y la solidaridad a partir de cuentos tradicionales. Como este video basado en "La niña de los fósforos» de Ándersen, realizado con la aplicación VideoScribe: «La cerillera y los refugiados» en https://www.youtube.com/watch?v=idClaDJdiGY.

- O bien el interés didáctico de una de las versiones digitales de un cuento de Andersen: EI soldadito de plomo. Booktrailer. Se trata de un pequeño corto a modo de cuenta cuentos con imágenes e intervenciones de los personajes realizadas con la aplicación FaceSwap; porque la creación de booktrailer nos parece una buena idea para fomentar la lectura en las aulas de secundaria: https://www.youtube.com/watch?$\mathrm{v}=\mathrm{a} 0 \mathrm{Cz} 3 \mathrm{raAqS} c \&$ feature $=$ youtu. be .

- En cuanto a la escritura digital a partir de poemas, este video-teatro basado en la poesía de Elsa Bornneman «Ay, qué disparate/ Se mató un tomate», en el que se lleva a cabo una dramatización en que los protagonistas de los versos son verduras parlantes.

- Escritura creativa utilizando las redes sociales más conocidas, porque en Twitter o en Facebook, se puede dar voz a distintos personajes. Así se hizo con múltiples cuentos tradicionales que se pueden consultar en Tropos, e incluso en un proyecto cervantino, en este video sobre el «Quijote en whatsapp». La actividad se puede replicar con cualquier obra literaria en las aulas de Primaria o Secundaria y favorece la empatía del alumnado con los personajes clave de la literatura: https://www.youtube.com/watch?v=iYqCWX722Pk.

En definitiva, este proyecto de escritura colaborativa digital es demasiado amplio para abarcarlo completo en estas páginas. Así que sobre todo el trabajo realizado a partir de los cuentos tradicionales se puede profundizar en mis otros artículos: «Desde los cuentos tradicionales hacia la escritura creativa 2.0. Propuesta didáctica» (Ocnos 2018, en prensa). En esta ocasión nos vamos a centrar en el otro género literario que se ha tomado como modelo para la escritura creativa en este proyecto: la poesía.

\footnotetext{
${ }^{3}$ Para profundizar en las propuestas didácticas con booktrailer para el aprendizaje de la literatura, se remite al artículo de Ballester-Roca, J. e Ibarra-Rius, Noelia (2016).
} 


\section{ANTOLOGÍAS POÉTICAS PARA LA EDUCACIÓN EN IGUALDAD}

Si todos nos sintiéramos hermanos.

(Pues la sangre de un hombre, ¿no es igual a otra sangre?)

Si nuestra alma se abriera (¿No es igual a otras almas?)

(Ángela Figuera, «Unidad»)

A través de la poesía para la educación emocional y de valores hemos querido contribuir en la medida de lo posible a despertar al mundo de la profunda crisis de emocional y solidaria que sufre y acercar el aprendizaje a la utopía (Salmurri 2014). La poesía en definitiva abre la mirada y la conciencia de los lectores, aumenta la empatía de niños y jóvenes porque les acerca a lo que sienten o han sentido otras personas de todas las culturas.

Incluimos a continuación una breve selección de la Antología por la igualdad de género que hemos realizado, y que se puede consultar en nuestra obra Versos para amar (2017), donde se representan desde las más antiguas Coplas populares hasta la poesía contemporánea:

Desde niña me casaron

por amores que no amé:

mal casadita me llamaré.

Madre mía, muriera yo,

y no me casara no.

(Cancionero musical de palacio, 154)

¡Ay!, cadenas de amar,

¡cuan malas sois de quebrar!

(Cancionero sevillano, fol. 272)

Ya la coge del cabello,

ya la camisa le rasga.

Corales tibios dibujan

arroyos en rubio mapa.

¡Oh, qué gritos se sentían

por encima de las casas!

Qué espesura de puñales

y túnicas desgarradas...

Violador enfurecido, Amnón huye con su jaca.

(Federico García Lorca)

Niña

Quizá te busquen

porque naciste,

quizá te midan por mujer.

Quizá te acosen

porque creciste,

quizá te odien por mujer. 
Pero no dejes

de ser la niña que abraza

todo lo que hay en si.

Pero no dejes de ver el mundo

como un espacio por compartir.

Quizá te insulten,

quizá no nazcas,

quizá te anulen por mujer.

Quizá no llegues a ser tú misma,

quizá te empujen por mujer.

Pero no dejes

de ser la niña que abraza

todo lo que hay en si.

Pero no dejes de ver el mundo

como un espacio por compartir.

(Pedro Guerra)

...Dentro me crecieron volcanes

que amenazaban explosionar.

Dentro me fue creciendo el deseo del cuerpo

de ser anís en un mar de grama.

Y dentro, muy dentro de mí,

comenzó a crecerme el hambre.

Hambre de leyes,

de palabras, de historias, de poemas...

Me empezó a crecer en el cuerpo

una mujer que no quería ser de nadie.

(Paz Martín Pozuelo,1958)

Miedo global (Patas arriba, La escuela del mundo al revés)

Es el tiempo del miedo.

Miedo de la mujer a la violencia del hombre

y miedo del hombre a la mujer sin miedo...

miedo a la noche sin pastillas para dormir

y miedo al día sin pastillas para despertar.

Miedo a la multitud, miedo a la soledad,

miedo a lo que fue y a lo que puede ser,

miedo de morir, miedo de vivir...

(Eduardo Galeano) 
¿No os avergüenza mirar

en tanto lugar de España

a tanta mujer serena

bajo tantas amenazas?

Un tiro por cada diente

vuestra existencia reclama,

cobardes de piel cobarde

y de corazón de caña.

Canción del esposo soldado (Vientos del pueblo)

...

Tus piernas implacables al parto van derechas,

y tu implacable boca de labios indomables,

y ante mi soledad de explosiones y brechas

recorres un camino de besos implacables.

Para el hijo será la paz que estoy forjando.

(Miguel Hernández)

Se buscan valientes

que apoyen y defiendan al débil.

Tú eres importante, tú sabes lo que pasa,

no mires a otro lado no le tengas miedo al malo.

Sé valiente y no permitas lo que viste ayer.

Si hay alguien que se siente solo,

si hay alguien al que han dejado apartado,

ponte en su lugar. ¡Yo ya estoy a su lado!

(Rap de Juan Manuel Montilla «El Langui»)

Nosotras también somos historia, nosotras también hacemos historia, nacemos y existimos.

Tomamos el tiempo entre las manos y sabemos llenarlas de amor y esperanza.

Aunque algunos nos ignoren, nos tachen de ilusas, locas, cierren los ojos o nos crean invisibles, no reconozcan nuestro talento, o quieran apagar nuestra voz, como se apaga una vela.

Pero ahí estamos...

(Encarnación Ortega,1972) 
Terminamos la antología con un poema escrito por una de nuestras alumnas y con otro de los ejemplos de remediación digital realizados por las estudiantes de la Facultad de Educación de la Universidad Complutense:

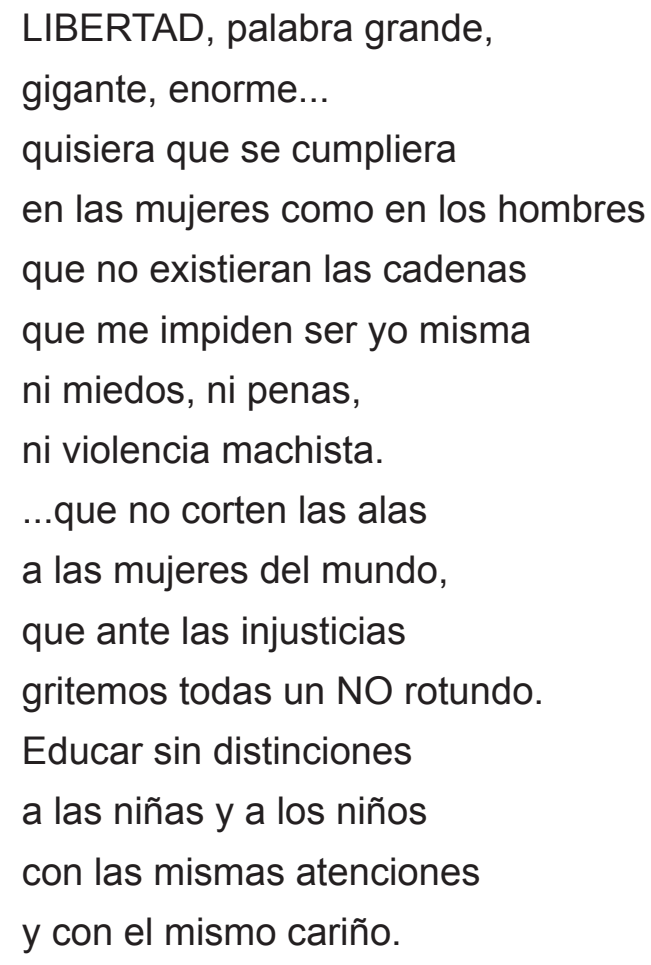

(Sonsoles Barrio, alumna de la ucm)

Video-relato que realiza una versión digital del cuento de Bretch: https://www.youtube.com/watch?v=UQHMbffIAPE (creado por las alumnas: Cristina Martín García, Andrea Mateo Martín y Ainhoa Olmos Frías).

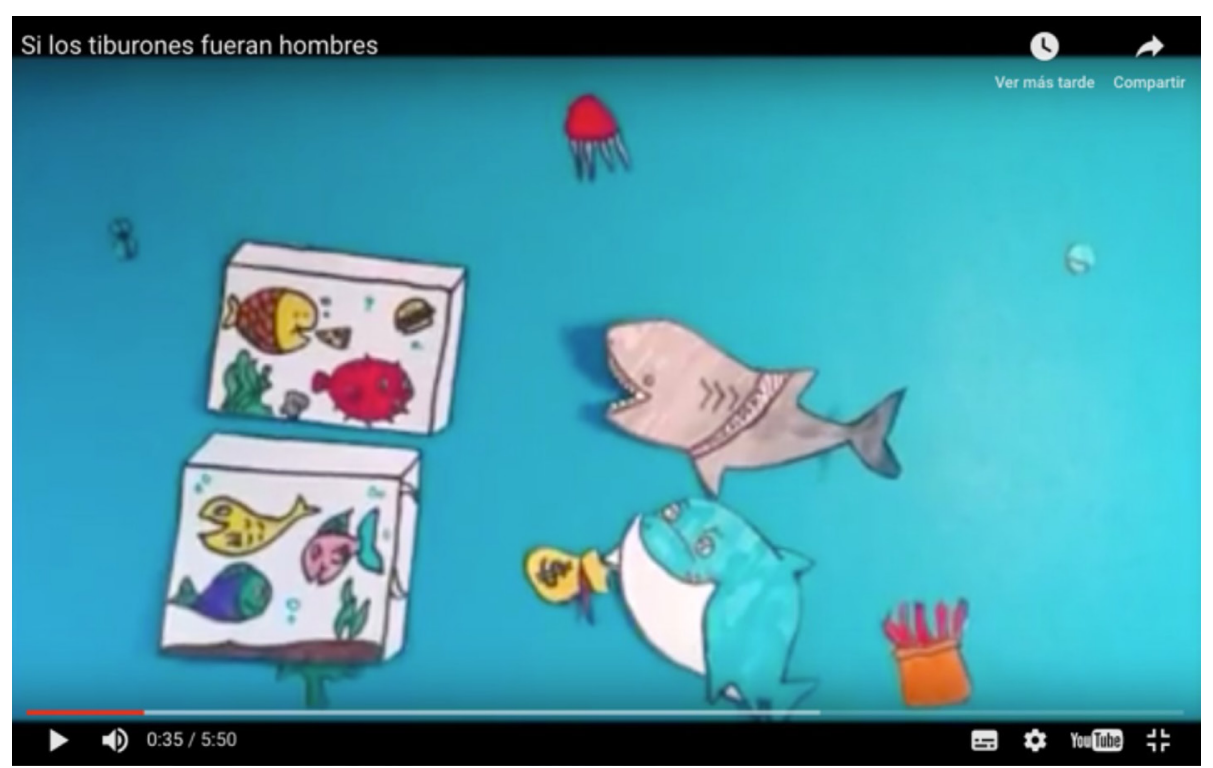




\section{CONCLUSIONES}

Cuerpo de la mujer, río de oro

Cuerpo de la mujer, fuente de llanto

\section{(Blas de Otero)}

En este proyecto se busca construir espacios educativos en los que se trabaje la igualdad y la colaboración, en los que el otro se sienta valorado y aceptado, condición indispensable para una educación en donde la cooperación entre las personas se imponga a la injusticia, en donde los alumnos adquieran esperanza y ánimo para no rendirse ante los problemas del mundo presente, sino para afrontarlos, para dejar que las conciencias críticas se desarrollen sin aprisionar los sueños en el campo de lo posible.

Con estos fines el mejor aliado didáctico lo vamos a encontrar en la literatura y más concretamente en la poesía universal que se ha preocupado ahora y siempre por los valores humanos. Así se ha hecho a través de la antología poética en torno a la igualdad de género de la que se haaportadounabrevemuestraenestacomunicación.Peroelproyectohaidomásalládedichasantologías, a partir de las que se ha trabajado la escritura creativa y digital, usando las tecnologías multimedia para motivar la lectura y la escritura en las aulas y a través de ella el desarrollo de una conciencia crítica personal.

La esperanza de la educación y de la vida es creer en la posibilidad de hacer lo inédito viable, porque no hay utopía verdadera fuera de la tensión entre la denuncia de un presente intolerable y la lucha hacia un futuro por crear. Toda utopía supone esa denuncia porque «Sin sueño y sin utopía, sin denuncia y $\sin$ anuncio, lo único que queda es el entrenamiento técnico al que la educación es reducida» (Freire, 2006).

\section{REFERENCIAS BIBLIOGRÁFICAS}

DELMIRO,B.(2002). La escritura creativa en las aulas. Entorno a los talleres literarios. Barcelona: Grao.

FREIRE, Paolo (2006): Pedagogía de la Indignación, Madrid: Morata.

GARCÍA CARCEDO, Pilar y REGUEIRO, Begoña (2014): El reto de escribir. Entre papeles y pantallas, Granada: GEU.

GARCÍA CARCEDO, Pilar (2008): Enseñanza virtual y presencial de las literaturas, Granada: Grupo Editorial Universitario (Editora, Grupo LEETHi).

(2011): Educación literaria y escritura creativa, Granada: GEU.

(2017): Versos para amar. Poesía para la educación emocional. Publicación online (Vid. Researchgate:

https://www.researchgate.net/publication/322676381_Educacion_emocional_Versos_para_amar).

y GOICOECHEA, María (2013): Alicia a través del espejo. Lecturas literarias del siglo XXI. Salamanca. Grupo de investigación LEETHi (Literaturas españolas y europeas del texto al hipertexto) (AMAZON).

GARDNER, John (2001): El arte de la ficción, Madrid: Ediciones y talleres de escritura creativa Fuentetaja.

GONZÁLEZ HUELVA, Diego (2000): Educación y solidaridad. Hacia una verdadera educación solidaria, en Comunicar 15 en: file:///Users/pilargarciacarcedo/Downloads/Dialnet-EducacionYSolidaridad- 230028.pdf.

ORTEGA, Esperanza (2011): El baúl volador, Valladolid: Col. Campo de Plumas. QUENEAU, Raymond (1987): Ejercicios de estilo, Madrid, Cátedra, $2^{a}$ edición.

LEVY, Marc (2001): Escritura y creatividad: un método para desarrollar ideas originales y resolver problemas en el trabajo: Paidós. MENDOZA, A. Y ROMEA, C. (COORD) (2010): El lector ante la obra Hipertextual, Horsori.

MOREU MALARET, Eduard (2017): «Realismo, utopías y sueños» en www.soldebo.org/sites/default/files/REALISMO_cuaderno_5.doc (Consultado el 9 de febrero de 2018).

MORENO, Victor (2012). Va de poesía. Pamplona: Pamiela.

RODARI, Gianni (2002): Gramática de la fantasía. Introducción al arte de contar historias, Barcelona: Planeta.

SALMURRI, F. (2004). Libertad emocional. Estrategias para educar las emociones. Barcelona: Paidós. 